\title{
Use of Gadolinium Contrast Adrenal Venography for the Assessment of Primary Aldosteronism in a Patient with lodine Allergy
}

\author{
HiROYUKi SASAMURA, SUBARU HASHIMOTO*, SACHIO KURIBAYASHI*, KOICHI UENO**, \\ ATSUSHI TAKASE, MATSUHIKO HAYASHI AND TAKAO SARUTA
}

Departments of Internal Medicine, School of Medicine, Keio University, Tokyo 160-8582, Japan

*Diagnostic Radiology, School of Medicine, Keio University, Tokyo 160-8582, Japan

**Emergency Medicine, School of Medicine, Keio University, Tokyo 160-8582, Japan

\begin{abstract}
Primary aldosteronism is a relatively common cause of secondary hypertension. It is often important to diagnose this disease accurately, since appropriate surgical therapy may result in cure of the disease. Assessment of the laterality of adrenal hyperfunction is possible using adrenal venous sampling of steroid hormones, but this procedure may not be feasible in patients with allergy to iodinated radiocontrast agents. In this paper, we report a patient with primary aldosteronism who was found to have bilateral adrenal tumors on CT. Because preoperative localization of the hyperfunctioning tumor was important, adrenal venous sampling and venography was performed by a highly-experienced radiologist using the MRI contrast agent gadolinium. After reviewing the data, the patient received a right adrenalectomy. This case report demonstrates that it was possible to perform adrenal venography using gadolinium in this patient, however the safety and efficacy should be re-assessed in individual cases.
\end{abstract}

Key words: Gadolinium, Venography, Primary aldosteronism

(Endocrine Journal 51: 487-492, 2004)

PRIMARY aldosteronism is a major cause of secondary hypertension which is characterized by excess secretion of aldosterone resulting in hypertension, hypokalemia, metabolic alkalosis and a variety of other metabolic changes. Recent studies have suggested that the incidence of this disease may be greater than expected previously, and can occur in the absence of the classical signs of disease [1].

Primary aldosteronism can be caused by both unilateral (for example, adrenal adenoma, unilateral adrenal hyperplasia, unilateral multiple micronodules, adrenal carcinoma) and bilateral lesions (for example, idiopathic hyperaldosteronism, primary adrenal hyperplasia, bilateral adrenal adenomas). It is possible to

Received: October 2, 2003

Accepted: August 13, 2004

Correspondence to: Hiroyuki SASAMURA, M.D., Ph.D., Department of Internal Medicine, School of Medicine, Keio University, 35 Shinanomachi, Shinjuku-ku, Tokyo 160-8582, Japan distinguish unilateral lesions from bilateral lesions to some extent from the hormonal data with or without stimulation/suppression, however definitive diagnosis requires demonstration of laterality in the hormonal function of the two adrenals. One way to demonstrate the laterality is with the iodinated radioisotope $\left[{ }^{125} I\right]$ iodocholesterol. However, the most reliable method remains adrenal venography with adrenal venous hormone sampling.

The use of radiocontrast agents is required for the visualization of the adrenal veins in order to direct the sampling of venous blood at different locations. However, patients with allergy to iodinated contrast agents present a major clinical dilemma, because the use of these agents could result in an anaphylactic reaction, which can be severe in some cases [2]. Recent reports have suggested that, in the case of arterial angiography, the use of an MRI contrast agent (gadolinium) can be used as an alternative contrast agent in patients with renal failure or iodine allergy [3-5]. In this 
paper, we report the use of gadolinium for adrenal venography in the assessment of unilateral adrenal adenoma.

\section{Case Report}

A thirty-three-year-old woman presented with muscle weakness. The weakness started in the lower extremities but spread to the upper body. On visiting a local clinic, the serum potassium was found to be $1.8 \mathrm{mEq} / \mathrm{L}$, so the patient was referred to this hospital. The patient had a family history of hypertension, and had previously been told that she was hypertensive, however she had avoided treatment. On physical examination, the patient's height was $165 \mathrm{~cm}$ and weight was $97.6 \mathrm{~kg}$. The blood pressure was $176 / 102 \mathrm{mmHg}$, and the pulse was $80 / \mathrm{min}$, regular. Muscle strength was grossly normal, and there were no neurological deficits or remarkable findings in heart, lung or abdomen.

The laboratory data were as follows: the complete blood count and coagulation tests were within the normal range. Serum total protein was $6.9 \mathrm{~g} / \mathrm{dL}$, total cholesterol was $204 \mathrm{mg} / \mathrm{dL}$, blood urea nitrogen was $5.5 \mathrm{mg} / \mathrm{dL}$, creatinine was $0.4 \mathrm{mg} / \mathrm{dL}$, uric acid was $5.0 \mathrm{mg} / \mathrm{dL}$, sodium was $140.8 \mathrm{mEq} / \mathrm{L}$, potassium was $2.4 \mathrm{mEq} / \mathrm{L}$, chloride was $99 \mathrm{mEq} / \mathrm{L}$, calcium was $7.7 \mathrm{mg} / \mathrm{dL}$, glucose was $188 \mathrm{mg} / \mathrm{dL}$, and creatinine kinase was $1660 \mathrm{IU} / \mathrm{L}$. The patient was admitted for evaluation. Blood gas analysis at room air was $\mathrm{pO}_{2}$ 83.2 torr, $\mathrm{pCO}_{2} 43.5$ torr, $\mathrm{pH} 7.479, \mathrm{HCO}_{3}{ }^{-} 32.0$ $\mathrm{mmol} / \mathrm{L}$. In the 24 hour urine collection, urine volume was $2500 \mathrm{~mL}$, creatinine was $1.53 \mathrm{mg} /$ day, sodium was $306.5 \mathrm{mEq} /$ day, potassium was $25.5 \mathrm{mEq} / \mathrm{day}$, chloride was $175 \mathrm{mEq} /$ day. Hormone data on admission are presented in Table 1.

In summary, the patient had hypertension, hypokalemia, metabolic alkalosis, with an increase in plasma aldosterone (Aldo) and urine aldosterone with suppression of plasma active renin concentration (ARC), suggesting the diagnosis of primary aldosteronism. Various hormonal tests were therefore performed to investigate the possibility that the patient had primary aldosteronism due to adrenal adenoma or hyperplasia. The results of these tests are summarized in Table 2. Firstly, the response of ARC and Aldo to furosemide injection was investigated, and it was found that ARC remained suppressed after furosemide injec-
Table 1. Endocrine studies (1)

\begin{tabular}{lll}
\hline & Patient values & Normal range \\
\hline Plasma hormones & & \\
Active renin (ARC) & $\underline{2.6 \mathrm{pg} / \mathrm{mL}}$ & $3.6-36.2$ \\
Aldosterone (Aldo) & $\underline{496 \mathrm{pg} / \mathrm{mL}}$ & $50-200$ \\
ACTH & $10 \mathrm{pg} / \mathrm{mL}$ & $7-56$ \\
Cortisol & $16.1 \mathrm{ug} / \mathrm{dL}$ & $3.5-18.4$ \\
DHEA-S & $78.0 \mathrm{ug} / \mathrm{dL}$ & $50-270$ \\
24-hour urine hormones & & \\
Aldosterone & $\underline{54.0 \mathrm{ug} / \mathrm{day}}$ & $0.6-9.0$ \\
Free cortisol & $38.5 \mathrm{ug} / \mathrm{day}$ & $11.2-80.3$ \\
17-OHCS & $7.6 \mathrm{mg} / \mathrm{day}$ & $2.6-9.0$ \\
17-KGS & $12.5 \mathrm{mg} / \mathrm{day}$ & $6.1-16.2$ \\
17-KS & $4.4 \mathrm{mg} / \mathrm{day}$ & $2.4-11.4$ \\
Adrenaline & $6.3 \mathrm{ug} / \mathrm{day}$ & $5.4-17.4$ \\
Noradrenaline & $88.2 \mathrm{ug} / \mathrm{day}$ & $38.1-144.7$ \\
Dopamine & $663 \mathrm{ug} / \mathrm{day}$ & $316-1272$ \\
VMA & $2.9 \mathrm{mg} / \mathrm{day}$ & $1.4-4.9$ \\
HVA & $2.9 \mathrm{mg} / \mathrm{day}$ & $1.6-5.5$ \\
Metanephrine & $0.06 \mathrm{mg} / \mathrm{day}$ & $0.05-0.20$ \\
Normetanephrine & $0.19 \mathrm{mg} / \mathrm{day}$ & $0.10-0.28$ \\
Androsterone & $0.77 \mathrm{mg} / \mathrm{g} \mathrm{Cr}$ & $0.30-3.46$ \\
Etiocholanolone & $0.58 \mathrm{mg} / \mathrm{g} \mathrm{Cr}$ & $0.25-2.93$ \\
11-oxoandrosterone & $0.03 \mathrm{mg} / \mathrm{g} \mathrm{Cr}$ & $0.00-0.07$ \\
11-oxoetiocholanolone & $0.34 \mathrm{mg} / \mathrm{g} \mathrm{Cr}$ & $0.03-0.71$ \\
11-hydroxyandrosterone & $0.77 \mathrm{mg} / \mathrm{g} \mathrm{Cr}$ & $0.23-1.46$ \\
11-hydorxyetiocholanolone & $0.24 \mathrm{mg} / \mathrm{g} \mathrm{Cr}$ & $0.02-0.57$ \\
DHEA & $0.54 \mathrm{mg} / \mathrm{g} \mathrm{Cr}$ & $0.03-3.94$ \\
\hline
\end{tabular}

Table 2. Endocrine studies (2) (furosemide test and diurnal variation)

\begin{tabular}{lccc}
\hline & $\begin{array}{c}\text { Before } \\
\text { furosemide }\end{array}$ & $\begin{array}{c}\text { After } \\
\text { furosemide }\end{array}$ & \\
\hline Aldosterone (Aldo, pg/mL) & 469 & 343 & \\
Active renin (ARC, pg/mL) & $<2.5$ & $<2.5$ & \\
\hline & $7 \mathrm{am}$ & $4 \mathrm{pm}$ & $11 \mathrm{pm}$ \\
\hline Cortisol (ug/dL) & 16.1 & 8.6 & 5.1 \\
ACTH (pg/mL) & 17 & 6 & 6 \\
Aldosterone (Aldo, pg/mL) & 469 & 343 & 270 \\
Active renin (ARC, pg/mL) & $<2.5$ & $<2.5$ & $<2.5$ \\
\hline
\end{tabular}

tion. The diurnal variations in adrenocortical steroids were also examined, and values of cortisol and Aldo at $11 \mathrm{pm}$ (cortisol $5.1 \mathrm{ug} / \mathrm{dL}$, Aldo $270 \mathrm{pg} / \mathrm{mL}$ ) were found to be slightly reduced compared to the values at $7 \mathrm{am}$ (cortisol $16.1 \mathrm{ug} / \mathrm{dL}$, Aldo $469 \mathrm{pg} / \mathrm{mL}$ ) (Table 2).

Various imaging studies were performed to localize the source of the excess aldosterone secretion. On abdominal ultrasound, a $17 \mathrm{~mm}$ hypoechoic mass was found in the right adrenal. Similarly, the abdominal 
MRI revealed a mass of about $20 \mathrm{~mm}$ of fatty density above the right kidney, compatible with an adrenal adenoma. On the other hand, the abdominal CT showed a $20 \mathrm{~mm}$ mass which was poorly enhanced after contrast enhancement, and also revealed a similar $8 \mathrm{~mm}$ mass in the left adrenal (Fig. 1). After the contrastenhanced CT examination, the patient developed wheezing and dyspnea. Piping sounds were also heard on auscultation. The timing of these symptoms was thought to be consistent with an allergic reaction to the iodinated radiocontrast agent.

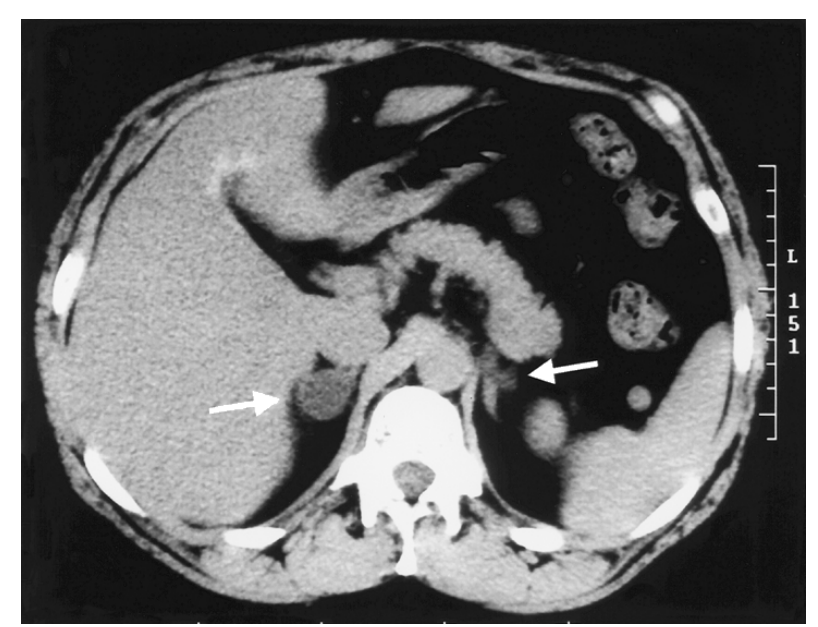

Fig. 1. Abdominal CT scan of this patient. The $20 \mathrm{~mm}$ right adrenal tumor and the $8 \mathrm{~mm}$ left adrenal tumor are shown with arrows.

\section{Right adrenal venography}

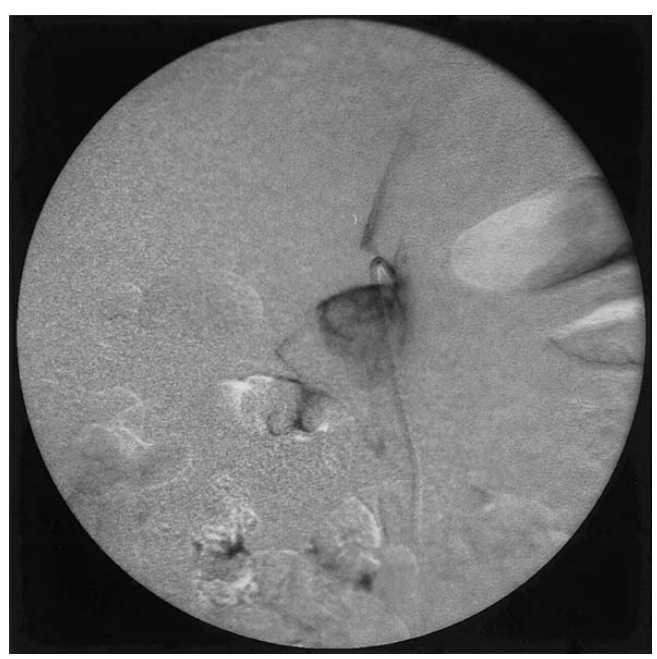

The investigations so far suggested the possibility of primary aldosteronism due to adrenal adenoma. However, since adrenal tumors were found in both the right and left adrenals by CT scan, the source of the excess aldosterone secretion was unclear. A full discussion was performed with the patient, the internal medicine team, and the radiology team. After explaining the risks and benefits, the patient requested the use of gadolinium as a radiocontrast agent to guide adrenal venous sampling. The results of this investigation are shown in Figs. 2 and 3. The technical aspects of the

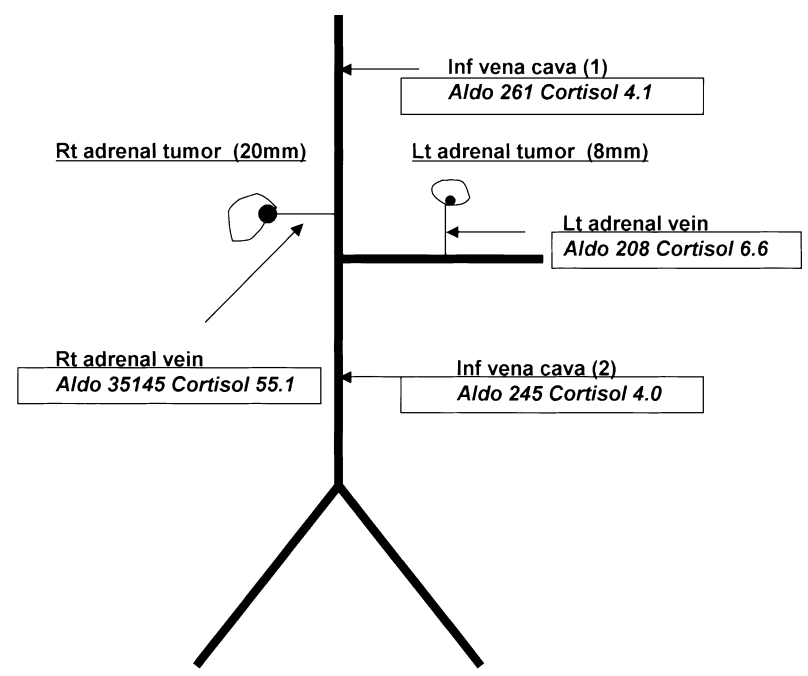

Fig. 3. Results of adrenal venous sampling. Aldo: aldosterone concentration $(\mathrm{pg} / \mathrm{ml})$; Cortisol: cortisol concentration (ug/dL).

\section{Left adrenal venography}

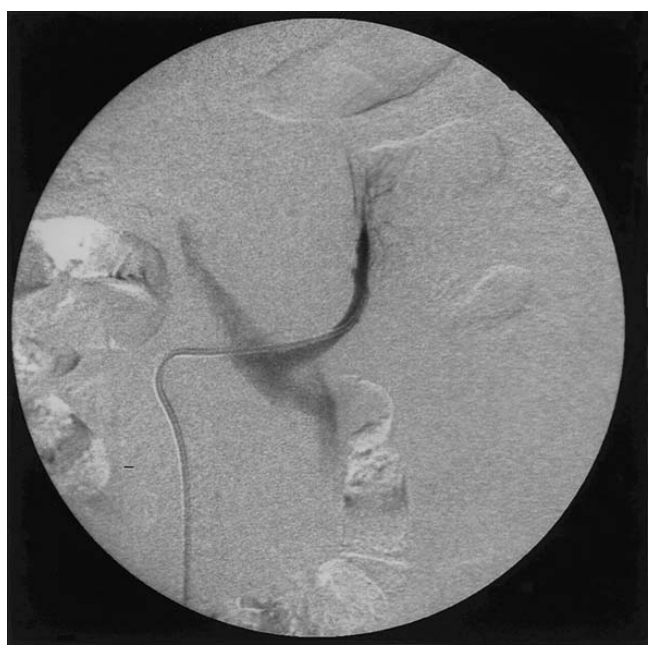

Fig. 2. Representative photograph of the gadolinium-contrast adrenal venography in this patient. 
procedure will be discussed elsewhere. The right and left adrenal veins were visualized using a total of $6 \mathrm{~mL}$ of sodium gadodiamide, and adrenal vein sampling was performed. The Aldo/cortisol ratio was markedly increased in the right adrenal vein.

No side effects were seen after this study. As a result of this study, the patient elected to have surgery on the right adrenal tumor. Laparoscopic adrenalectomy was performed on the right adrenal tumor, and the postoperative course was unremarkable. Photomicrographs of the excised cortical adenoma and surrounding adrenal tumor tissue are shown in Fig. 4. On histological examination, tumor cells with foamyappearing cytoplasm with oval nuclei were visible in an alveolar pattern, and sinusoid vessels were seen in the interstitium. Some fat cells and compact cells were seen $(<10 \%)$, but no evidence of malignancy was found. The surrounding adrenal tumor tissue was not atrophic. These findings were considered by the pathologist to be compatible with primary aldosteronism due to adrenal adenoma. When the patient was last seen in this hospital's outpatient clinic one month after the operation, her blood pressure had fallen to $125 / 80 \mathrm{mmHg}$ (on valsartan $20 \mathrm{mg}$ /day), and her potassium ARC and Aldo were within the normal range (sodium $137.8 \mathrm{mEq} / \mathrm{L}$, potassium $4.5 \mathrm{mEq} / \mathrm{L}$, chloride $100 \mathrm{mEq} / \mathrm{L}$, ARC $42 \mathrm{pg} / \mathrm{mL}$, Aldo $42 \mathrm{pg} / \mathrm{mL}$, ACTH 43 pg/mL, cortisol $13.0 \mathrm{ug} / \mathrm{dL}$ ).

\section{Adrenal tumor tissue}

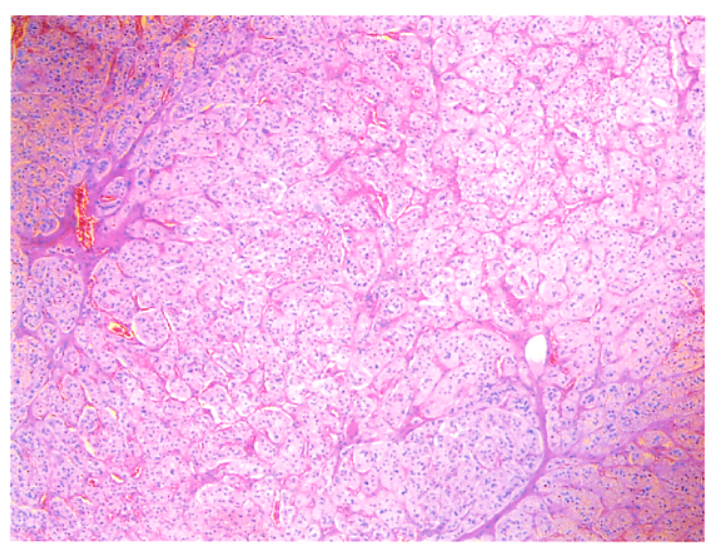

\section{Discussion}

Iodinated radiocontrast agents are routinely used for angiography. Although there are wide variations between different reports, it has been estimated that the incidence of anaphylactoid reactions to ionic hyperosmolar radiocontrast agents ranges from $0.1 \%$ to $5 \%$, with lower values (less than $0.5 \%$ ) for non-ionic lower osmolar preparations [6-8]. Symptoms of radiocontrast allergy include dermatologic symptoms such as rash, itching, erythema, urticaria, gastrointestinal symptoms such as nausea, vomiting, and respiratory symptoms such as wheezing and dyspnea. In some cases, more severe symptoms such as anaphylactic shock, convulsions, and even death have been reported.

In one series, Lang et al. reported that the incidence of such allergic reactions was 73 out of 5264 patients (1.39\%) [2]. Of interest, more of the patients (51 versus 22 men) were female, and women were also more susceptible to severe reactions [2]. The patient in this study was also female, and was suspected to have allergy to iodinated compounds because of the typical symptoms and clinical course after her contrastenhanced CT scan. This was a problem, because it was important to determine the functionality of the two tumors in this patient, because the patient did not want to continue anti-hypertensive medication since she was thinking of having a child in the future. However, it was unclear which of the two tumors was producing the excess aldosterone in this patient.

\section{Adjacent adrenal tissue}

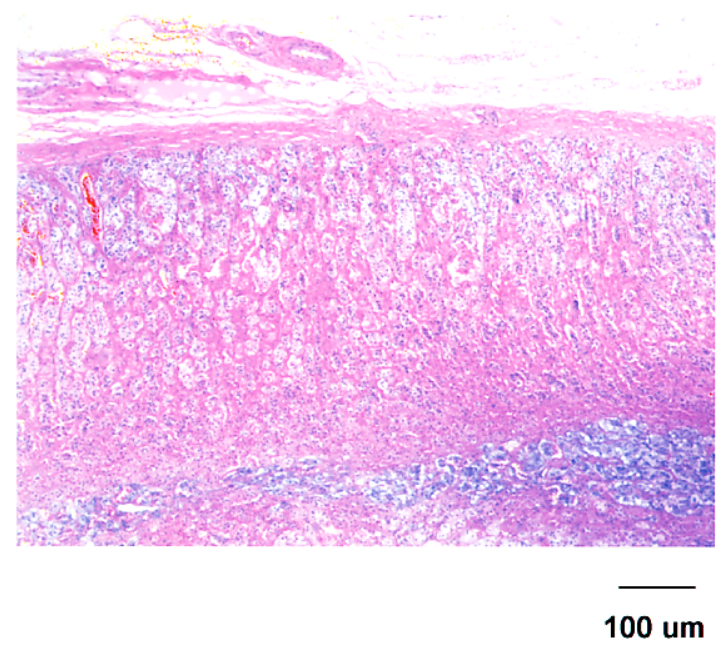

Fig. 4. Photomicrographs of adrenal tumor and adjacent adrenal tissue histology. Hematoxylin-eosin stain. Original magnification $\times 200$. 
One potential method of determining the laterality of adrenal function is adrenal scintigraphy using $\left[{ }^{131} \mathrm{I}\right]$ iodocholesterol. The amount of iodine in the injected $\left[{ }^{131} \mathrm{I}\right]$-iodocholesterol is almost negligible, and it may be possible to use this radioisotope in patients with iodine allergy. However, the drug information sheet listed a contraindication in patients with allergy to iodinated compounds, so the test was discontinued. A more reliable method to diagnose unilateral hyperfunction is adrenal venous sampling. However, the patient obviously was anxious about the possibility of recurrence of an anaphylactoid reaction.

One potential method to treat such patients is to use premedication before angiography [7, 9]. Marshall and Lieberman compared three pretreatment protocols to prevent anaphylactoid reactions to radiocontrast media in patients with a previous anaphylactoid reaction. Patients were pretreated with either prednisone and intramuscular diphenhydramine, or prednisone, diphenhydramine, and cimetidine, or prednisone, diphenhydramine, cimetidine and ephedrine before the procedure. Despite these pretreatments $6-8 \%$ of the patients in each of the treatment groups experienced a repeat anaphylactoid reaction [9].

Recent reports have suggested that gadolinium chelates may be a useful alternative to iodinated contrast media for angiography and interventional radiology. Kinno et al. first reported the use of gadolinium chelate for intraarterial DSA in 1993 [4]. Subsequently, Spinosa et al. reported the use of gadolinium for percutaneous transluminal angioplasty of patients with renal failure due to renal artery stenosis $[5,10]$. Kaufman et al. successfully performed carotid arteriography in patients with a serum creatinine of about $1.5 \mathrm{mg} / \mathrm{dL}$, and reported that renal function was not decreased by the contrast media $[3,11]$. These reports highlighted the fact that gadolinium chelates can be used relatively safely in patients with renal dysfunction or renal failure. $\mathrm{CO}_{2}$ gas has also been used as a radiocontrast agent. Similar to gadolinium, $\mathrm{CO}_{2}$ can be used in patients with renal dysfunction or radiocontrast allergy. However, $\mathrm{CO}_{2}$ gas is technically difficult to use, and the image resolution may be inferior [12].

To our knowledge, there are few reports at present concerning the use of gadolinium chelates for venography of the adrenal veins. However, in this case we used this agent because diagnosis of the hyperfunctioning adrenal tumor was important for the diagnosis, and because of the request of the patient to use this agent. As a result of the study, the most probable source of excess aldosterone was assessed to be the right adrenal tumor. The possibility that the left adrenal also produced aldosterone could not be completely ruled out. Nevertheless, the patient elected to receive laparoscopic adrenalectomy.

Several caveats are required in the application of the results of this case report to other patients. Firstly, although no adverse reactions were noted in this patient, the possibility that a reaction to gadolinium may occur should be considered, and the risk/benefit assessed in individual cases. For example, Cochran et al. reported that the adverse reaction rate to gadolinium contrast material was $0.06 \%$ [8]. Similarly, Murphy et al. reported that out of 74,275 gadodiamide injections, 11 $(0.015 \%)$ nonallergic and $12(0.016 \%)$ mild allergylike reactions occurred [13]. The incidence of adverse events after injection of MR contrast agents was much higher $(15 \%)$ in a Chinese population, but most of these were non-specific adverse events [14]. Secondly, the procedure was performed by a skilled radiologist who was experienced in locating the adrenal veins, and the amount of contrast required (about $6 \mathrm{~mL}$ of $32.3 \%$ gadodiamide hydrate, infused by slow injection (approximately $1 \mathrm{~mL} / \mathrm{second}$ )) was less than the normal dose used, for example, in gadolinium MR angiography $(8-20 \mathrm{~mL})$. Visualization of the adrenal vein was much less clear than the image obtained using conventional iodinated contrast material, so it is unclear whether this method is suitable for more inexperienced radiologists. In fact, the cortisol concentration in the left adrenal vein was lower than in the right adrenal vein, which could suggest the possibility that the catheter inserted in the left adrenal vein was dislodged or poorly positioned, however the positioning of the catheter was constantly confirmed by direct visualization. Therefore this method should be considered only by experienced radiologists. Thirdly, the cost of the radiocontrast agent could not be provided by the health insurance. For these reasons, it is best that the risks and benefits are assessed, and the patient's full consent is obtained before considering this procedure, in accordance with institutional guidelines. 


\section{References}

1. Omura M, Sasano H, Fujiwara T, Yamaguchi K, Nishikawa T (2002) Unique cases of unilateral hyperaldosteronemia due to multiple adrenocortical micronodules, which can only be detected by selective adrenal venous sampling. Metabolism 51: 350-355.

2. Lang DM, Alpern MB, Visintainer PF, Smith ST (1995) Gender risk for anaphylactoid reaction to radiographic contrast media. J Allergy Clin Immunol 95: 813-817.

3. Kaufman JA, Hu S, Geller SC, Waltman AC (1999) Selective angiography of the common carotid artery with gadopentetate dimeglumine in a patient with renal insufficiency. AJR Am J Roentgenol 172: 1613-1614.

4. Kinno Y, Odagiri K, Andoh K, Itoh Y, Tarao K (1993) Gadopentetate dimeglumine as an alternative contrast material for use in angiography. AJR Am J Roentgenol 160: 1293-1294.

5. Spinosa DJ, Matsumoto AH, Angle JF, Hagspiel KD (1998) Use of gadopentetate dimeglumine as a contrast agent for percutaneous transluminal renal angioplasty and stent placement. Kidney Int 53: 503-507.

6. Lieberman P (1991) Anaphylactoid reactions to radiocontrast material. Clin Rev Allergy 9: 319-338.

7. Greenberger PA, Patterson R (1991) The prevention of immediate generalized reactions to radiocontrast media in high-risk patients. J Allergy Clin Immunol 87: 867872.

8. Cochran ST, Bomyea K, Sayre JW (2001) Trends in adverse events after IV administration of contrast media. AJR Am J Roentgenol 176: 1385-1388.

9. Marshall GD Jr, Lieberman PL (1991) Comparison of three pretreatment protocols to prevent anaphylactoid reactions to radiocontrast media. Ann Allergy 67: 7074.

10. Spinosa DJ, Angle JF, Hagspiel KD, Schenk WG 3rd, Matsumoto AH (1998) CO2 and gadopentetate dimeglumine as alternative contrast agents for malfunctioning dialysis grafts and fistulas. Kidney Int 54: 945-950.

11. Kaufman JA, Geller SC, Bazari H, Waltman AC (1999) Gadolinium-based contrast agents as an alternative at vena cavography in patients with renal insufficiency-early experience. Radiology 212: 280-284.

12. Caridi JG, Stavropoulos SW, Hawkins IF Jr (1999) $\mathrm{CO} 2$ digital subtraction angiography for renal artery angioplasty in high-risk patients. AJR Am J Roentgenol 173: 1551-1556.

13. Murphy KP, Szopinski KT, Cohan RH, Mermillod B, Ellis JH (1999) Occurrence of adverse reactions to gadolinium-based contrast material and management of patients at increased risk: a survey of the American Society of Neuroradiology Fellowship Directors. Acad Radiol 6: 656-664.

14. Chu WC, Lam WW, Metreweli C (2000) Incidence of adverse events after I.V injection of MR contrast agents in a Chinese population. A comparison between gadopentetate and gadodiamide. Acta Radiol 41: 662666. 